\title{
O MUNDO ORDENADO DE ELEONORE KOCH: QUESTÕES DA "VISUALIDADE PURA" NA PINTURA FIGURATIVA DA ARTISTA, A PARTIR DE SUAS OBRAS NA COLEÇÃO THEON SPANUDIS (MAC-USP)
}

\section{Fernanda Pitta (Universidade Cidade de São Paulo - Unicid)}

A trajetória da artista Eleonore Koch (1926) se destaca entre os percursos da arte brasileira de sua geração. Fugindo da Alemanha nazista, chega ao Brasil em 1936, com sua mãe, a psicanalista Adelheid Koch, primeira mulher a exercer a atividade clínica de psicanálise entre nós.

Interessada a princípio por escultura, Eleonore Koch freqüenta os ateliês de artistas emigrados ou descendentes, de origem alemã ou européia, em meados dos anos 1940. Tem aulas com Yolanda Mohalyi, Elizabeth Nobiling, Samson Flexor e Bruno Giorgi. No final dos anos 1940, após o fim da Guerra, retorna à Europa e estuda escultura com Arpad Szenes e Robert Coutin. Dessa fase, quando a pintura ainda não tinha sido a escolha da artista, não temos testemunhos em museus públicos que possam ser observados, nem foram, até o momento, localizados exemplares de sua produção em coleções privadas.

De volta a São Paulo, em 1952, exerce por um curto período a profissão de cenógrafa na TV Tupi. Por intermédio do artista Geraldo de Barros, consegue um trabalho como secretária de Mario Schemberg ${ }^{1}$. Por insistência de Theon Spanudis, a quem conhece por razão das atividades psicanalíticas da mãe e que havia se tornado seu analista, trava contato com o pintor Alfredo Volpi, que, de maneira bastante peculiar, vem a se tornar seu mestre.

É no ateliê de Volpi que Koch aprende a pintura em têmpera, observando, não sem relutância do pintor $^{2}$, a sua técnica - desde a escolha do tema, das cores, até a execução da composição. É também lá que Eleonore recebe as lições sobre aquilo que Volpi considerava como a tarefa fundamental do pintor, a de "resolver do quadro", lembrando da lição de Ernesto de Fiori e seu desprezo pela pintura "de assunto" 3.

\footnotetext{
${ }^{1}$ Gonçalves Filho, s.d., s.p.

${ }^{2}$ Em entrevista a Lorenzo Mammì e João Bandeira, Koch afirma que Volpi não a deixava observar a preparação dos pigmentos. Entrevista, 2005, acervo do Centro Universitário Maria Antonia.

${ }^{3}$ Sobre essa questão ver: Mammì, 1999, especialmente páginas 14 a 25.
} 
A formação com Volpi nos autoriza a pensar certamente que, para a artista, a pintura não era questão de "assunto". Mas como explicar que em toda a sua trajetória a figuração manteve-se presente como um traço forte de sua problemática? Em outras palavras, o que busca a pintura de Eleonore Koch ao insistir na representação figurativa, explorando seus impasses e limites? Tal compromisso torna-se ainda mais intrigante diante do fato de que boa parte dos artistas brasileiros vai migrar, nos anos 1950, para a abstração seja de matriz informal ou geométrica, inclusive seus primeiros professores, Yolanda Mohalyi, Elisabeth Nobiling e Bruno Giorgi. Também Volpi, nesse período, flertará com o concretismo produzindo obras concretas, aproximando-se dos artistas do grupo Ruptura. Tal movimento, comum aos artistas americanos ${ }^{4}$, gerará fortes disputas que se condensam em torno da recepção das bienais de 1957 (a famosa Bienal tachista) e 1959 e podem ser acompanhadas nos manifestos como os do grupo Ruptura e textos como os de Mario Pedrosa.

Wolfgang Pfeiffer, ao apresentar a exposição em comemoração à doação de Spanudis ao MAC-USP, em 1980, pondera a inclusão das obras de Koch, entre outros, na coleção do psicanalista, por se tratarem de "pinturas de frações figurativistas mais pictóricas", distinguindo-as daquelas pertencentes a um campo construtivo mais estrito, e de "acento mais forte", obras de "artistas com intuito mais organizador, no sentido de confrontar signos e elementos de concentração formal" 5. Aqui se encontrariam Volpi, Mira Schendel e Sacilotto, entre outros (apesar dos dois primeiros não poderem ser considerados não-figurativos, sobretudo no recorte de sua obra presente na coleção).

Spanudis, no mesmo catálogo, faz comentários bastante elucidativos de sua interpretação a respeito do construtivismo brasileiro, no qual vê e aprecia uma aliança de rigor formal à temática metafísica e muitas vezes religiosa, freqüentemente tingida de aspectos psicológicos e dramáticos. A apreciação da pintura de Eleonore aparece como uma concessão: "dos figurativos atuais, admiramos por causa de seus excepcionais requintes plásticos a pintura de Odriozola, Fang e Eleonore

\footnotetext{
${ }^{4}$ Para o debate do contexto norte-americano, ver Belting, 2006, especialmente o capítulo 6, "Arte ocidental: a intervenção dos Estados Unidos na modernidade do pós-guerra".

${ }^{5}$ Coleção Theon Spanudis, 1980, s.p. texto de Wolfgang Pfeiffer.
} 


\section{Koch”. ${ }^{6}$ Atenção cedida pelos seus aspectos plásticos, mas também por aquilo que Spanudis identificava como seu pendor metafísico. \\ Lorenzo Mammì, em catálogo da recente exposição da coleção Theon Spanudis no centro Universitário Maria Antonia esclarece:}

"Spanudis aproximava a pintura de matriz concretista ou abstrata à arte popular, tentando encontrar em seus esquemas formais um sentido espiritual, de certa maneira atemporal. Por isso colecionava, junto com as obras de vanguarda, brinquedos, arte naif, registros de pinturas de parede."7

Será portanto, por um viés de certa maneira narrativo e alegórico que Spanudis interpretará a pintura de Eleonore Koch, interpretação esta que marcará a sua recepção crítica ao longo desses anos, como testemunha aqui o comentário de Olívio Tavares:

"Embora a temática de Eleonore não seja volpiana - a não ser em certas naturezas mortas que se relacionam com quadros de Volpi dos anos 40 -, há, em sua maneira de tratá-la, um certo distanciamento contemplativo e metafísico que vem do Volpi daquela época"s

É o aspecto de transcendência que atrai Spanudis para a arte de Koch e dos demais artistas que classifica como construtivos:

"A arte transcendente é aquela que ultrapassa o imediatismo que a obra apresenta, ofertando-nos e proporcionando-nos vivências luminosas que variam entre o magismo dos que tem origens na mesclagens com as culturas dos afrobrasileiros e ameríndios (Rubem Valentim, Niobe Xandó, Valdeir Maciel, Jandyra Waters, Milton Dacosta e o primitivo José Antonio da Silva), como também o magismo mítico e mediterrâneo de Fernando Odriozola até as vivências mais contemplativas e cosmicamente dissolventes (como o Zen de um Fang, Eleonore Koch, Mira Schendel, Volpi, Arnaldo Ferrari), e das formas contidas e sofridas de uma Tomie Ohtake.

Todos estes artistas contribuem para uma nova religiosidade anônima e leiga, sem dogma, mito e rito estabelecidos, como nas religiões organizadas e oficializadas".

\section{Para Spanudis, Koch:}

"Sacraliza os objetos de uso diário. Contra a nossa mania profana de usar tudo como objeto de imediato consumo, ela reganha para o simples objeto sua dimensão sacral. Os amplos espaços sensíveis (que não são os espaços vazios e mortos dos matemáticos e cientistas), fazem parte integral de sua intenção de ressacralizar o objeto perdido no fluxo constante do consumo mecânico. Uma secreta poesia emana dos seus coloridos, objetos, configurações estranhas e seus espaços amplos e humanos."

\footnotetext{
${ }^{6}$ Coleção Theon Spanudis, 1980, s.p. texto de Theon Spanudis.

${ }^{7}$ Mammì, 2005. s.p.

${ }^{8}$ Volpi, Permanência e matriz: 7 artistas de São Paulo, 1986. Texto de Olívio Tavares.
} 


\section{II}

A recente exposição da Coleção Spanudis no CEUMA-USP pôde proporcionar, com a reunião das obras desse acervo, um recorte de interpretação do trabalho de Eleonore, recolocando-o no contexto dos debates entre figuração e abstração, concretismo e abstração informal.

Certamente Eleonore aprende com Volpi uma pintura de "gestos ritmados, de uma desigualdade de carga de pigmento no começo e no final da pincelada, e de uma luminosidade especial que resulta da tempera a ovo" "Entretanto, o seu figurativismo parece ter sido um obstáculo à compreensão dos problemas visuais enfrentados por sua pintura, daí a insistência de Spanudis nas características transcendentes e metafísicas do seu trabalho, como que para compensar a sua não adesão ao construtivismo "puro".

Para muitos críticos, entre eles Mario Schemberg, a exploração da visualidade da pintura só poderia se dar através da libertação das formas representacionais. É assim que Schemberg vê, por exemplo, o desenvolvimento da pintura de Volpi:

“a libertação das formas representacionais permitiu a Volpi desenvolver ainda mais o sentimento da espacialidade pura, já tão notável na série das marinhas de Itanhaém do período de 1940-42. A espacialidade pura adquire uma vibração belísisima pela maestria no uso das grandes massas de tons puros, uma descoberta original de Volpi. Nessas composições as cores puras em têmpera são tratadas de modo a eliminar a impressão de matéria, dando puros espaços intensamente coloridos em tons uniformes." 10

A pintura figurativa não é tratada no mesmo patamar. Schemberg não a considera uma forma de pesquisa, mas concessão à encomenda e ao gosto dominante:

"Na obra de Volpi devemos distinguir as telas pintadas para deleite próprio das que tem feito por encomenda, que naturalmente correspondem mais ao gosto da clientela. Há vários anos ele vem recebendo encomenda de madonas e santos. Nessa parte figurativa de sua obra recente, há uma influência perceptível dos primitivos italianos, assim como da nossa arte popular religiosa. A capacidade de síntese, a pureza do colorido e a beleza da composição de muitas dessas telas são notáveis, mas em conjunto apresentam menos interesse do que a sua pintura abstrata ou semi-abstrata do mesmo período." 11

\footnotetext{
${ }^{9}$ Volpi, Permanência e matriz: 7 artistas de São Paulo, 1986. Texto de Olívio Tavares.

${ }^{10}$ SCHEMBERG, 1961. p. 38.

${ }^{11}$ SCHEMBERG, 1961, p.38.
} 
Certamente é possível colocar esse rebaixamento da pintura figurativa dentro do quadro de disputa ideológica que cindiu a arte moderna brasileira no final dos anos 1940 e início dos anos 1950. De um lado, a pintura figurativa de caráter social, cujo epíteto seria Candido Portinari. De outro lado, as novas experiências de construtivos e concretos, representados por Waldemar Cordeiro e o grupo Ruptura, mas também Volpi e os cariocas do grupo Frente. ${ }^{12}$

Mas como situar nesse debate a pintura de Eleonore Koch? O que a torna intrigante e singular nesse contexto foi - e essa argumentação que gostaria apenas de delinear aqui - sua perseverança em manter-se no sistema figurativo, apesar da possível pressão desse ambiente da arte moderna no Brasil por uma opção por um construtivismo de cepa nãofigurativa.

É claramente cabível analisar seu trabalho pelo viés do universo interior, de personalidade feminina. Seus objetos comparecem sempre isolados do contato com os entornos de cor, sugerindo analogias psicológicas e metafísicas. Entretanto, é possível escapar à idéia de ressacralização dos objetos proposta por Spanudis. O caráter tipificado de seus objetos pode sugerir uma outra escala de relações, que talvez passem por uma radicalização de alguns procedimentos construtivos sem o abandono do registro figurativo ou, inclusive, da exploração de aspectos do registro figurativo, testando-os até os seus limites, por caminhos derivados, ou até mesmo diferentes, daqueles explorados anteriormente pelos mestres do modernismo, Cézanne, Picasso e Matisse.

12 Para essas questões cf., por exemplo, Arte Moderna em Contexto, 2006. Texto de Fernando Cocchiarale, no qual cita a conferência de Portinari intitulada "Realismo e Abstracionismo", publicada no Boletim SATMA (Sul América Terrestres, Marítimos e Acidentes). Rio de Janeiro, n.23, p.47, 1949. 


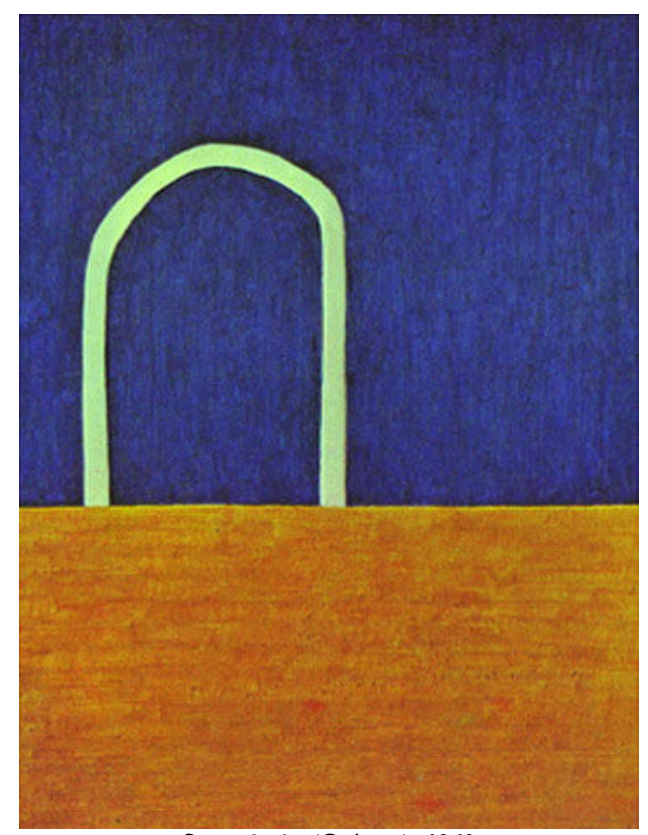

\section{Sem título (O Arco), 1960 \\ Têmpera sobre tela $91,8 \times 72,8 \mathrm{~cm}$}

Coleção Theon Spanudis, Museu de Arte Contemporânea da Universidade de São Paulo

Analisemos, brevemente, o quadro de 1960 da Coleção Spanudis, intitulado pelo colecionador O Arco. Duas massas de cor dividem a tela um pouco abaixo de sua metade.

\section{Bibliografia}

ARTE transcendente: exposição de pintura. Apresentação de Luiz Seraphico. Texto de Theon Spanudis. São Paulo: MAM, 1981.

ARTE Moderna em Contexto. Coleção AMN Amro Real. São Paulo: Banco Real, 2006. Texto de Fernando Cocchiarale.

BELTING, Hans. O fim da história da arte. São Paulo: Cosac e Naify, 2006.

COLEÇÃO Theon Spanudis: doação para o acervo do Museu de Arte Contemporânea da Universidade de São Paulo. Apresentação de Wolfgang Pfeiffer. Texto de Theon Spanudis. São Paulo: MAC/USP, 1980.

FOLHA ON LINE. Exposição "Natureza Morta" leva acervo do MAM para a BM\&F. Folha Oline, 2/04/2003. Em: http://www1.folha.uol.com.br/folha/ilustrada/ult90u31805.shtml 
GONÇALVES FILHO, Antonio. "Eleonore Koch e sua pintura intimista”. Especial Eleonore Koch Estadão.com.br. Em: http://www22.estadao.com.br/ext/especial/eleonorekoch/galeria/

MAMMI, Lorenzo. Volpi. São Paulo: Cosac \& Naify,1999. (Série espaços da arte brasileira)

MAMMI, Lorenzo. Apresentação da exposição Coleção Theon Spanudis. Catálogo. Centro Universitário Maria Antonia da USP, 2005.

PFEIFFER, Wolfgang. Artistas alemães e o Brasil. São Paulo: Empresa das Artes, 1996.

SALÃO PAULISTA DE ARTE MODERNA, 4, São Paulo, 1955. Catálogo. São Paulo: Galeria Prestes Maia, 1955.

SCHEMBERG, Mario. "Volpi" in: CATÁLOGO da VI Bienal de São Paulo, Museu de Arte Moderna, Setembro a Dezembro de 1961.

VOLPI: permanência e matriz: 7 artistas de São Paulo. Texto de Olívio Tavares de Araújo. São Paulo: Montesanti Galleria, 1986. 